\title{
A SIMPLE METHOD OF FUSION OF THE SUBTALAR JOINT IN CHILDREN
}

\author{
Austin Brown, Brighton, England \\ From the Heritage, Chailey, and the Alexandra Hospital for Sick Children. Brighton
}

The number of children in whom subtalar stabilisation is indicated is diminishing, largely because of the disappearance of anterior poliomyelitis, which so often accounted for an unstable valgus foot, with or without fixed equinus, and less often a calcaneo-varus or cavo-varus foot. Cerebral palsy is quite often associated with valgus accompanied by supination of the forefoot. The latter can become a fixed deformity at an early age unless valgus is controlled. The severely paralysed limb associated with meningomyelocele may also present the problem of an unstable foot and here again early stabilisation can prevent fixed deformity. Neonatal sciatic palsy is still seen occasionally, and with it equinovarus deformity. In such cases transfer of the tendon of an acting tibialis posterior muscle to the front of the foot, combined with subtalar stabilisation, can give a very good result. Lastly, arthrodesis may be necessary in cases of peroneal spasm to relieve both pain and spasm.

Formal subtalar fusion with excision of the joint surfaces is to be avoided in children under the age of eleven to twelve because it may interfere with growth of the foot. Extra-articular fusion has the advantage of not interfering with growth, and this led Grice (1952) to advocate it in young children. The technique that he advocated was to place cortical bone grafts taken from the upper tibia into the sinus tarsi. Initially he confined this method to patients with valgus after poliomyelitis, but he later widened the scope of the operation to include cases of cerebral palsy, spina bifida and severely pronated feet of otherwise normal children.

Armstrong (1943) described a method of fusing the subtalar joint in fractures of the calcaneus by driving a tibial graft through the neck of the talus into the calcaneus after excision of the joint surfaces.

The method to be described was suggested by Mr J. S. Batchelor at Guy's Hospital and I have used it since 1953. A fibular graft is used, and as this is removed subperiosteally the gap left in the fibula rapidly disappears. The subtalar joint is not exposed.

Initially it was intended to provide stability until growth of the foot had stopped, when formal stabilisation could be effected. So far this has been found necessary in only two cases. Although the fusion is not strictly extra-articular in that quite often the posterior end of the anterior talo-calcaneal joint is traversed by the graft, this has not interfered significantly with bone growth in the cases observed.

It is of interest that Harris (1955) found that peroneal spasm might occur when there was an incomplete bone bridge between the talus and calcaneus, but never when the bridge was complete. He noted the later development of talo-navicular arthritis. This of course is a possibility after operative fusion of the talo-calcaneal joint; but, whereas the congenital bridge is associated with a valgus foot, an important step in the operation to be described is to place the calcaneus in a neutral position before inserting the graft.

\section{TECHNIQUE OF OPERATION}

The aim of operation is to place a fibular graft through the neck of the talus across the sinus tarsi into the calcaneus.

A tourniquet is used. A short vertical incision is made over the dorsum of the foot in line with the head and neck of the talus. The neck of the talus is exposed. One tends to work too far forwards on the talus and it is an advantage to open the ankle at the upper end of the incision 
in order accurately to define the neck of the talus. The calcaneus is now inverted under the talus and held in this position while an awl is driven through the neck of the talus, downwards, slightly laterally and backwards. As the awl pierces the inferior surface of the talus it will be felt to traverse the sinus tarsi until it meets the resistance of the upper surface of the calcaneus.

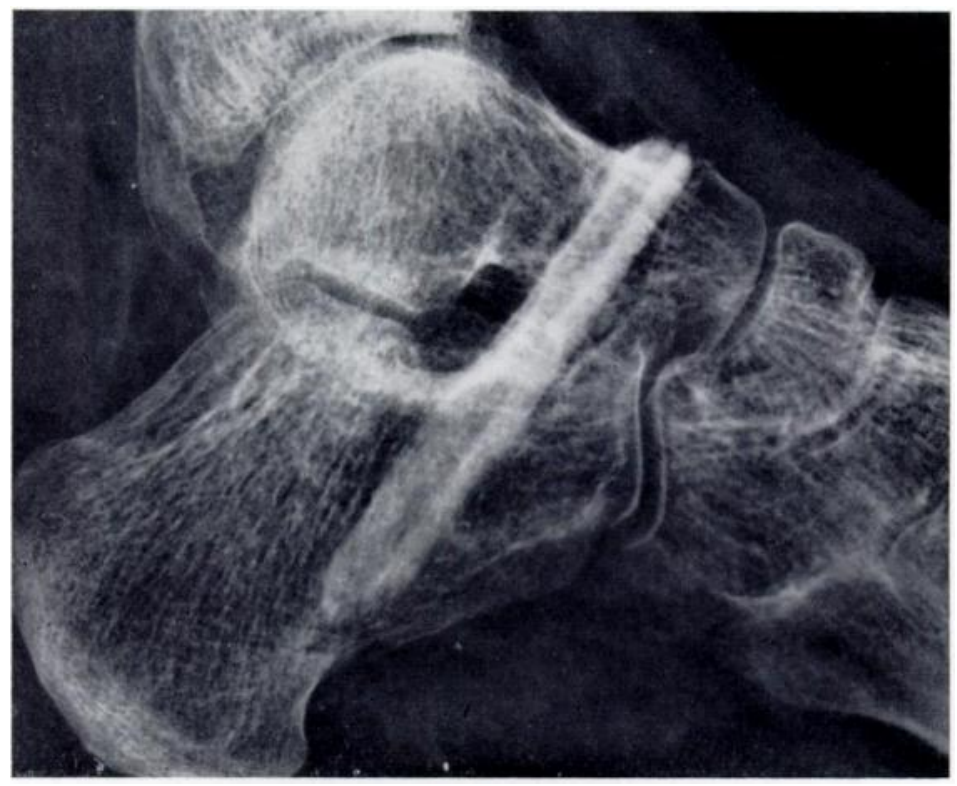

FIG. 1

The graft in place.

It is driven onwards for two or three centimetres. With the awl in position, attempts to manipulate the foot into valgus will reveal marked stability and resistance to eversion. The track is enlarged with a burr, a head of nine millimetres diameter being the right size for most cases. Only occasionally has a twelve millimetres diameter burr been needed for older children.

A straight lateral incision is made to expose the middle third of the fibula and a subperiosteal graft about five centimetres long is removed. The narrow end is trimmed to a point which is driven through the track made into the talus and calcaneus (Fig. 1). The wound is then closed and a below-knee plaster is applied. In two weeks this is changed to an unpadded walking plaster, which is worn for a further six weeks.

TABLE 1

INDICATIONS FOR OPERATION

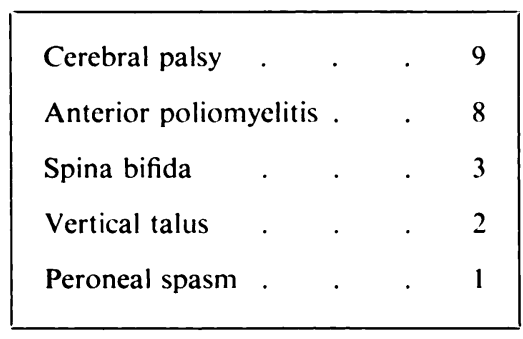

RESULTS

Twenty patients (twenty-three feet) have been followed up over the past ten years. The indications for the operation are shown in Table I. The average age was eight years and four 
months; the oldest child was fifteen and the youngest one and a half. The average length of follow-up was four years and a half, the longest being ten, and the shortest two.

Stability with survival of the graft was maintained in seventeen patients for at least four years. The graft is intact in two other patients operated upon less than four years ago.

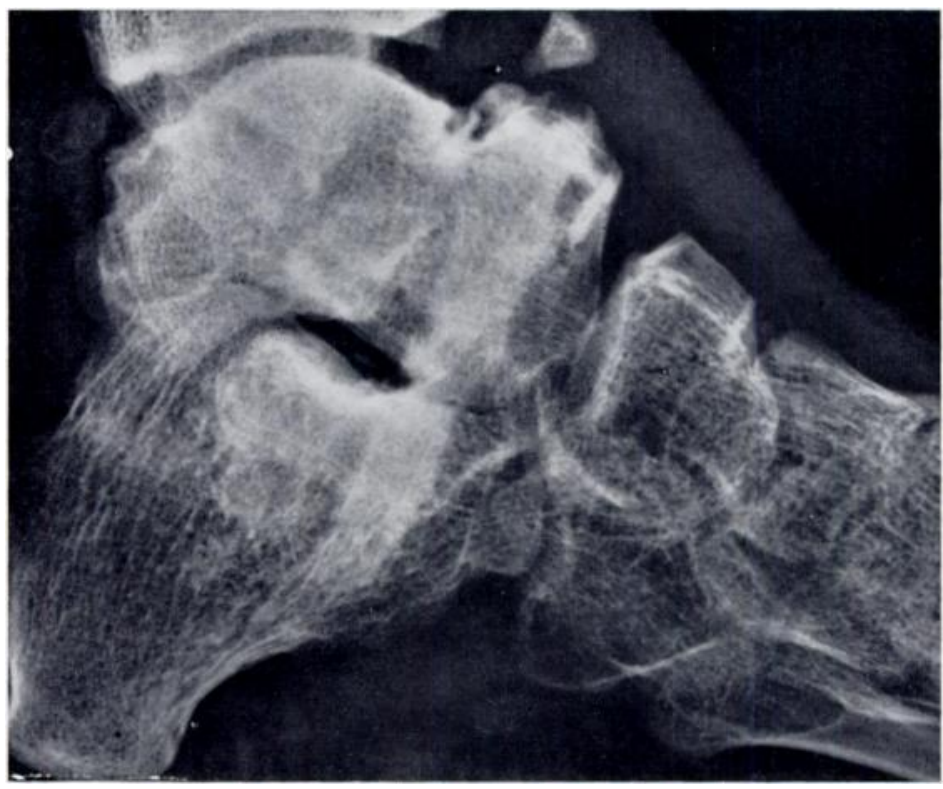

Fig. 2

Radiograph eighteen months after operation showing fracture of the graft.

In two patients, both heavy boys of fifteen and over, having suffered from poliomyelitis, the grafts broke within eighteen months after operation; obviously neither was suitable for this operation (Fig. 2). Grafts inserted into two feet with vertical talus have survived but have failed to hold the correction obtained, and I would not use the method again for this condition.

\section{SUMMARY}

1. A simple method of subtalar fusion, suitable for use in children, is described.

2. Although it is intended to provide stability for some years until a complete subtalar fusion can be carried out, further operation may not be necessary.

3. Its use is not advocated over the age of eleven or twelve.

\section{REFERENCES}

Armstrong, J. R. (1943): Posterior Subastragaloid Arthrodesis in Fractured Os Calcis. Lancet, 2, 506. GrICE, D. S. (1952): An Extra-Articular Arthrodesis of the Subastragalar Joint for Correction of Paralytic Flat Feet in Children. Journal of Bone and Joint Surgery, 34-A, 927.

HARRIS, R. I. (1955): Rigid Valgus Foot due to Talocalcaneal Bridge. Journal of Bone and Joint Surgery, 37-A, 169. 